\title{
Religião e espiritualidade no ensino e assistência de enfermagem
}

\author{
Religion and spirituality in education and nursing assistance \\ Religión y espiritualidad en la educación y asistencia de enfermería
}

\author{
Maria Aparecida Gussi', Jane Lynn Garrison Dytz' \\ 'Universidade de Brasília. Departamento de Enfermagem. Brasília, DF
}

Submissão: 02/05/2008

Aprovação: 29/05/2008

\section{RESUMO}

Estudo da interseção entre o discurso da enfermagem e os preceitos Que albergam a religião/religiosidade e espiritualidade, e como se deu a incorporação e o reflexo desse discurso nas práticas assistenciais, no ensino e no delineamento da organização da profissão. Para revisão bibliográfica, utilizaram-se as bases de dados LILACS e BDENF, da Biblioteca Virtual de Saúde. Um total de 57 artigos completos, publicados entre 1957 e 2007, foram analisados à luz das idéias sobre "memória coletiva”, de Maurice Halbwachs. Verificou-se Que há uma raiz religiosa com ramificações profundas na conformação da enfermagem brasileira. Esta configuração está tão imbricada na memória coletiva Que, mesmo com a expansão de instituições Que não se declaram religiosas, os pressupostos cristãos se mantêm presentes e com vitalidade.

Descritores: Enfermagem; Religião; Espiritualidade.

\begin{abstract}
Intersectional study between nursing discourse and precepts which embrace religion/religiousness and spirituality, and how these were incorporated and their reflection upon nursing practice, education and the history of the organization of the profession. For bibliographic review LILACS and BDENF databases of the Electronic Health Library were used. A total of 57 full-text articles, published from 1957 to 2007, were analyzed upon the light of the ideas of Maurice Halbwachs, about "collective memory". The results show that Brazilian nursing has a religious root with profound ramifications on its development. This configuration is so embedded in the collective memory that, even with the expansion of non-religious institutions, the Christian precepts remain present and strong.
\end{abstract}

Descriptors: Nursing; Religion; Spirituality.

\section{RESUMEN}

Estudio de la intersección entre el discurso del oficio de enfermera y preceptos que alojan la religión/el religiosidad y el espiritualidad, y como ha dado la incorporación y a la consecuencia de este discurso en los asistencias prácticos, la educación y la delineación de la organización de la profesión. Para la revisión bibliográfica, las bases de datos LILACS y BDENF de la Biblioteca Virtual de Salud, fueron utilizadas. Un total de 57 artículos completos, publicados entre 1957 y 2007, fueron analizados a la luz de las ideas en "memoria colectiva”, de Maurice Halbwachs. Se verificó que hay una raíz religiosa con ramificaciones profundas en la conformación del oficio de enfermera brasileño. Esta configuración es tan imbricada en la memoria colectiva Que, mismo con la expansión de las instituciones Que non se declaran religiosas, el presupuestos cristanos se mantiene presentes y con vitalidad.

Descriptores: Enfermería; Religión; Espiritualidad. 


\section{INTRODUÇÃO}

A religião ocupa um lugar privilegiado na história da enfermagem brasileira. Às vezes, uma chega a ser porta-voz da outra na formulação de um pensamento e na consolidação de atitudes Que influenciam a formação e o exercício profissional dos enfermeiros e auxiliares de enfermagem.

$\mathrm{Na}$ linguagem de Bitencourt Filho ${ }^{(1)}$, existe uma matriz religiosa com uma complexa interação de idéias e símbolos Que se amalgamaram num decurso multissecular Que resultou na gestão de uma mentalidade religiosa, uma representação coletiva. Para o autor, essa mentalidade expandiu sua base social, por meio de injunções incontroláveis, para, num determinado momento histórico, ser incorporada definitivamente ao inconsciente coletivo nacional.

Diante dessa conformação, buscou-se verificar Quais os pontos de interseção entre o discurso da enfermagem e os preceitos Que albergam a religião/religiosidade e espiritualidade, como se deu a incorporação e o reflexo desse discurso nas práticas assistenciais, no ensino e no delineamento da organização da profissão.

A junção dessas três entidades se deve ao fato de, na essência, referirem-se ao Que está em oposição ao profano, ao Que diz respeito ao espírito, à alma, ou seja, ao Que se condensa pela crença e elaboração de práticas em cujo cerne está a perspectiva de algo diferente da matéria.

\section{MÉTODO}

Parte-se do pressuposto de Que matérias veiculadas por meios Que têm o aval do universo acadêmico são formadoras de opinião e, conseQüentemente, direcionam ações e atitudes tanto no Que se refere à produção científica Quanto no exercício da profissão, na esfera do ensino, da assistência, como também no traçado de diretrizes políticas em espaços pertinentes à profissão ou com eles compartilhados. Com base nisso, foi feito um levantamento bibliográfico, na Biblioteca Virtual de Saúde (BVS), de artigos indexados nas bases de dados do Sistema LILACS (Literatura LatinoAmericana e do Caribe de Informação em Ciências da Saúde) e BDENF (Base de Dados da Enfermagem) $)^{(2)}$.

A escolha da BVS foi pautada em dois pontos. Um deles está ligado à transformação na área das comunicações, pois a internet é hoje o meio de difusão em Que há maior facilidade de acesso. Isso tanto no Que se refere à rapidez para se obter a informação Quanto a recursos tecnológicos disponíveis, o Que a torna amplamente utilizada, portanto passível de exercer forte influência na construção das práticas profissionais. A BVS alimenta a sua base com artigos Que tem assegurado as garantias de Qualidade devido ao rigoroso processo de revisão dos pares, uma vez Que são oriundos de revistas cujos conselhos editoriais são reconhecidos na comunidade.

Os artigos foram obtidos por meio do cruzamento de descritor "enfermagem" (Que alberga 103 descritos relacionados às especificidades da enfermagem) com os descritores "religião" e "espiritualidade" e as palavras truncadas "relig\$" e "espiritual\$". Este procedimento permitiu identificar todos os resumos de artigos em Que os radicais relig e espiritual fizessem parte da composição do texto, independente da forma como foram empregados.

Na primeira fase da busca, os termos religião e espiritualidade foram alocados dentro de um mesmo conjunto, uma vez que se pretendia trazer à luz um pensamento Que perpassasse tanto as organizações institucionais Quanto as vivências pessoais. Isso resultou na identificação de 76 artigos. Em seguida, fez-se uma depuração dos mesmos, utilizando-se como critério de inclusão a exigência de se discutir, de alguma forma, essa temática, o que resultou na seleção final de 68 artigos, publicados entre 1957 a 2007. Foram então identificados os textos completos online, nas bibliotecas da ABEn e da Universidade de Brasília, resultando para análise um total de 57. Após leitura cuidadosa e minuciosa e definição das categorias (História, Ética e Assistência), foi feita a análise do pensamento expresso em relação à religião, espiritualidade e enfermagem, utilizando-se como referencial teórico as idéias sobre "memória coletiva", de Maurice Halbwachs ${ }^{(3)}$. Esse autor concebe Que a evocação e a localização das lembranças têm sua gênese em Quadros sociais reais; e estes são peças fundamentais na reconstrução da memória. Refere Que há dois tipos de memória, a histórica - onde há uma reconstrução dos dados fornecidos pelo presente da vida social, Que é projetada no passado reinventado - e a memória coletiva, Que recompõe magicamente esse passado.

Para Halbwachs ${ }^{(3)}$, as ações e atitudes não são processos meramente atribuídos ao indivíduo: "o Que vemos hoje toma lugar no Quadro de referências de nossas lembranças antigas, inversamente essas lembranças se adaptam ao conjunto de nossas percepções presentes". E

para evocar seu próprio passado, em geral a pessoa precisa recorrer às lembranças de outras, e se transporta a pontos de referência Que existem fora de si, determinados pela sociedade. Mais do Que isso, o funcionamento da memória individual não é possível sem esses instrumentos, Que são as palavras e as idéias, Que o indivíduo não inventou, mas tomou emprestado de seu ambiente ${ }^{(3)}$.

\section{RESULTADOS E DISCUSSÃO}

\section{História: resgate de uma dívida $x$ conflito de paradigma}

"Um dos objetivos da história talvez seja justamente lançar uma ponte entre o passado e o presente, e restabelecer essa continuidade interrompida" ${ }^{(3)}$. Esta assertiva se reflete no conjunto de trabalhos aqui categorizados.

O Brasil tem uma raiz colonizadora religiosa Que marcou profundamente a organização do Estado e, em particular, a organização da assistência à saúde, seja controlando o ensino, seja exercendo uma função caritativa, mantendo sob sua responsabilidade administrativa a maioria dos hospitais, principalmente os destinados a indigentes.

Essa herança, advinda da disseminação do pensamento cristão, transformou o cuidado aos doentes, dantes realizado por mulheres, como peculiar a uma condição feminina, a uma das formas de caridade adotadas pela igreja e Que conjuga com a história da enfermagem. Os ensinamentos de amor e fraternidade transformam não somente a sociedade, mas também o desenvolvimento da enfermagem, marcando, ideologicamente, a prática de cuidar do outro e modelando comportamentos Que atendessem a esses ensinamentos. [...] a enfermagem passou a ser uma atividade de 
penitência Que se realizava como meio de purgação e purificação ${ }^{(4)}$.

O cristianismo desenhou com clareza este projeto. Cabe a nós, no nosso tempo histórico, compreender como isso foi sedimentado, como foi dado corpo a um ideário institucional Que possibilitou criar formas e estratégias Que pudessem sustentá-lo e impregnar a sociedade dos valores professos. Halbwachs ${ }^{(3)}$ afirma que "para a história tudo está ligado, por isso cada uma das transformações deve reagir sobre as outras partes do corpo social e preparar aqui e ali uma nova mudança", mudança esta Que se inscreve não só na linha do tempo como também no aQui e agora vivido.

Mediante estas prerrogativas, os trabalhos analisados nesta categoria foram agrupados de acordo com as vertentes Que a espelham: marcos filosóficos Que delinearam as ações religiosas na assistência à saúde, o controle das instituições de saúde por grupos religiosos, a inserção do postulado religioso na formação profissional, a organização em entidades de classe.

Padilha ${ }^{(5)}$ analisa a construção de um modelo pré-profissional no século XIX a partir do regimento do novo hospital da Santa Casa de Misericórdia do Rio de Janeiro ( 1852 ), por ocasião da chegada das irmãs de caridade da Congregação de São Vicente de Paula. Elas "imprimiam sua marca na prática da enfermagem Que se segue até os dias de hoje, principalmente nas Qualidades esperadas da Enfermeira, como obediência, humildade, abnegação, serviço ao próximo, disciplina, respeito à hierareuia, entre outras". A autora afirma em seu estudo Que "este ideal de comportamento molda as ações de enfermagem até os dias de hoje, influenciando o pensamento e o imaginário social”(5).

Ela conclui seu processo reflexivo apontando Que "a construção das relações de poder e das funções exercidas pelas pessoas Que ocupam o espaço hospitalar parece ter sido seminal no Que tange à construção de um modelo ideal de enfermeira brasileira" ${ }^{(5)}$. Esta afirmação corrobora com Halbachs ${ }^{(3)}$, Quando discute o tempo na construção de uma memória coletiva e sustenta a tese de Que Quando se acompanha a vida de um grupo, como a igreja, durante o período de sua evolução, vê-se Que o seu pensamento refletiu a vida de outras sociedades contemporâneas.

A propagação dos pressupostos cristãos estava também impregnada no cerne das lideranças da enfermagem. Em 1961, o XV Congresso Brasileiro de Enfermagem e II Congresso Brasileiro Latino-Americano do CICIAMS (Comitê Internacional Católicos de Enfermeiras e Assistentes Médico-Sociais), Que tiveram como tema o sentido cristão de servir e a enfermagem, assim Qualifica o trabalho em enfermagem: "é por isso que Quanto mais consciência tomamos da grande missão do homem, mais compreendemos o Que significa SERVIR, na linguagem cristã. Servir é dar-se. Dar-se a Deus para cumprir a missão Que Ele nos preparou, como Cristo realizou a missão Que lhe foi confiada pelo Pai”(6). Já Molina define Que servir significa estar a serviço de outro. O sentido cristão de servir na enfermagem nasceu com o advento de nosso Senhor Jesus Cristo. [...] a enfermeira exercendo sua profissão deve servir com sentido cristão. Com grande dose de ternura, com caridade bem dirigida a todos os Que, por QualQuer motivo, necessitem de sua ajuda ${ }^{(7)}$.

Mesmo a enfermagem moderna, liderada por Florence Nightingale, foi calcada em pressupostos cristãos $^{(8,9)}$. Nesse sentido, admite-se Que "enQuanto o real evangelho estiver sendo banido da prática de enfermagem, o ser humano não estará sendo cuidado plenamente. E a arte de enfermagem não fará sentido"(10). Esta postura tem sua gênese na cultura, na classe social à Qual pertencia o profissional e nas estruturas em Que se dava a assistência à saúde.

Boaventura Santos ${ }^{(1)}$ traz uma figura metafórica Que coaduna com este fato. Quando se refere ao uso de espelho por indivíduos e pela sociedade, assim se expressa:

espelhos da sociedade não são físicos, nem de vidros. São conjuntos de instituições, normatividades, ideologias Que estabelecem correspondências e hierarquias entre campos infinitamente vastos e práticas sociais. São essas correspondências e hierarquias Que permitem reiterar identificações até o ponto de estas se transformarem em identidades. A ciência, o direito, a educação, a informação, a religião e a tradição estão entre os mais importantes espelhos da sociedade. O Que eles refletem é o Que as sociedades são ${ }^{(1)}$.

Os hospitais foram tratados como campo fértil para difundir os ideais cristãos, e uma forma eficiente para alcançar esta meta era manter o controle tanto dos assistidos Quanto dos trabalhadores ${ }^{12-}$ 14). Esses trabalhos buscaram compreender a atuação das religiosas dentro de instituições psiquiátricas de Curitiba e Florianópolis, e apontam para uma vida condizente com o postulado Que pregavam: "mostra a submissão, abnegação e a religiosidade com Que as Irmãs se dedicavam à vida e ao trabalho em detrimento de si, com uma espécie de mortificação do seu eu, mas por outro lado, também reflete o poder silencioso das mesmas, manifesto pelo controle econômico e administrativo do trabalho"(14) e "o cuidar santificado exercido por essas mulheres fazia parte da identidade religiosa"(12).

Essa identidade não se expandiria se ficasse restrita aos muros das instituições assistenciais. Então as religiosas se enveredaram também para a ampliação de instituições de ensino, com a missão de "molda(r) a postura da futura enfermeira, aumentar o desejo de saber e despertar o amor pelo serviço ao próximo". Desse modo, "a identidade dos mestres, das religiosas e das profissionais Que atuavam no campo de prática, eram os modelos ideais a serem seguidos"(15), devendo-se "aliar o preparo técnico-científico com os compromissos da vida religiosa"(16). Figueiredo ${ }^{(17)}$, ao estudar o perfil dos auxiliares de enfermagem da cidade de Campinas, mostra Que ainda não se conseguiu encontrar uma postura equilibrada entre a competência técnica a relação de ajuda, desvinculando a enfermagem da caridade, e aponta Que a direção em Que a profissão caminha está também relacionada à visão dos profissionais Que são formados.

Para consolidação desta prerrogativa, a Revista Brasileira de Enfermagem apresenta um artigo Que sugeriu "a criação de uma disciplina nas escolas de enfermagem: Medicina Pastoral para preparar as futuras enfermeiras para a assistência espiritual ao paciente, ou fazê-lo através de cursos intensivos ou palestras"(18). Dentre os motivos Que justificariam tal procedimento, é apresentado às enfermeiras o dever de "inserir-se no campo dos enfermos, como Cristo se inseriu, e nessa busca ela [...] aprende a comungar o coração de Cristo Que se encarna na humanidade de seu povo, fala a sua linguagem, conhece a sua psicologia”(18).

$\mathrm{Na}$ abertura de uma reunião com lideranças de enfermagem, foi rezada uma missa pelo arcebispo do Rio de Janeiro, e a diretora da Escola de Enfermagem Anna Nery - EEAN, da Universidade Federal do Rio de Janeiro - UFRJ, assim se posicionou: a missa se justificava 
pela oportunidade de receber as bênçãos de Deus e de Nossa Senhora [...] vale ressaltar Que eram comuns os rituais católicos na EEAN, o que significa dizer que, de modo bastante expressivo, as professoras desta escola investiam na produção, reprodução, difusão e consumo dos bens de salvação, e assim, estariam legitimando as propriedades materiais e simbólicas, no caso, a doutrina católica, associada à posição da EAN na estrutura social. Esse tipo de orientação teve repercussões no Que se refere ao aumento do número de Escolas de Enfermagem de orientação católica, na década de $40^{(19)}$.

Nas entrelinhas, os textos revelam uma aliança entre a Igreja e o Estado que data dos primórdios da enfermagem e perpassa pela implantação da enfermagem moderna - "nos primeiros anos de vida da escola (Ana Nery), a decisão das candidatas por realizar o curso de enfermagem baseava-se na religiosidade (renúncia aos prazeres) e no espírito patriótico (ser útil ao país) [...], vocação, desejo de servir, trabalhar para os ideais da eugenia e, em menor proporção, na independência econômica ${ }^{(20)}$-, deixando rastros nos dias atuais.

Através de um pacto entre o governo de Getúlio Vargas e a Igreja Católica foram criadas a Escola de Enfermeiras do Hospital São Paulo (1938) e a Escola de Enfermagem de São Paulo (1942). A primeira foi conseQüência de uma aliança sólida entre a Arquidiocese do estado de São Paulo e a Escola Paulista de Medicina, através do Dr. Álvaro Guimarães Filho, por orientação governamental. E a segunda deu-se por meio de um acordo entre a Fundação Rockfeller e o governo de São Paulo, cujo teor definia Que a escola seria nos moldes da Escola Ana Nery ${ }^{(15,21)}$ e de outras onze escolas espalhadas nas diversas regiões do país(21).

Halbwachs ilustra a compreensão desses fatos ao discutir a memória coletiva e o tempo em relação ao estado e à igreja; e afirma Que "Quando o Estado subordina a igreja, Quando a preenche com seu espírito, a Igreja se torna um órgão do estado e perde sua natureza de sociedade religiosa"(3).

Outra estratégia Que os textos reportam diz respeito à organização em entidades de classe: a União das Religiosas Enfermeiras do Brasil - UREB tinha como meta "reunir as enfermeiras-religiosas em um grupo distinto"; e, após ter seu estatuto aprovado, filiaram-se ao Comitê Internacional Católicos de Enfermeiras e Assistentes Médico-Sociais - CICIAMS. Entre seus objetivos, destacam: "estimular em todos os países, a criação, o desenvolvimento de associações profissionais católicas a fim de assegurar apoio moral e espiritual às enfermeiras e assistentes médico-sociais católicas, bem como aperfeiçoamento técnico". Criou-se, também, a União Católica de Enfermeiras do Brasil UCEB, cuja meta era a de "estabelecer entre seus membros uma união fraterna em Cristo, favorecendo-lhes uma vida profissional eficiente e em espírito apostólico"(22,23).

Como expressão de gratidão às enfermeiras que lideraram esses movimentos, há dois artigos. Num deles, as autoras colocam-no como tentativa de "homenagear dívida" com as enfermeiras religiosas, em especial as Que atuaram na $\mathrm{ABEn}$, num recorte temporal Que vai até $1976^{(23)}$; o outro discorre sobre as representações acerca da prática associativa da ABEn-Piauí ${ }^{24)}$.

Podemos fazer a releitura desses cenários à luz de uma visão gramisciana. Para Gramsci, a igreja constitui uma das engrenagens essenciais do Estado, um aparelho ideológico. Constitui-se numa das principais formas de concepção do mundo, e a "estrutura dos sistemas políticos e religiosos e suas relações recíprocas são, pois, amplamente influenciadas pela existência e a força de castas intelectuais tradicionais" (25).

\section{Ética}

Como concretizar esses pressupostos em valores a ser incorporados? Como criar resistências Que possam se opor às forças Que tendem a transformar a forma de ser e de agir de um grupo? Quando explana sobre memória coletiva e espaço, e ao se dirigir às sociedades religiosas, Halbwachs ${ }^{(3)}$ nos provoca com a reflexão de Que "elas estão fundamentadas em uma comunidade de crenças Que tem como objetivo seres imateriais, essas associações estabelecem laços invisíveis entre seus membros".

Esses laços são fortalecidos num movimento Que Kant chamou de união em uma cidade ética [...] embora cada um obedeça a seu dever privado, pode-se extrair disso uma harmonia contingente de todos em vista de um bem comum, [...] instituição de uma comunidade submetida às leis morais, cujas forças associadas são tanto mais eficazes para resistir aos ataques do princípio do mal ${ }^{(26)}$.

O "viver ético", tema do Congresso Brasileiro de Enfermagem ${ }^{(27)}$, traz uma orientação para o ensino de graduação sob o ponto de vista do cristianismo, faz uma retrospectiva do pensamento de São Tomas de Aquino - "a razão verdadeira e a fé nunca poderão ser contraditórias porQue ambas vem da mesma fonte de toda a verdade, o Ser Absoluto" -, passa por Nightingale - com o pensamento de Que "as leis da ciência são as leis de Deus Que o homem vem desvendando" - e pela formulação de idéias de vários filósofos. Por fim, conclui Que "a ética tem como o objetivo maior o desenvolvimento no homem da capacidade de utilizar o processo intuitivo espiritual, ou, em outras palavras fazer prevalecer em si, o homem novo, - considerando o velho, a natureza carnal fortalecendo os valores espirituais à custa da mortificação".

Nesta mesma direção, Trevizan ${ }^{(28)}$, ao analisar a dimensão moral e a ação ética no trabalho gerencial da enfermeira, afirma que "a dimensão espiritual sustenta e supera a intelectual, a estética e a moral”, e que o homem integra a dimensão espiritual em sua vida mesmo Que não a reconheça. Conclui então Que "a crise enfrentada atualmente pelo homem e Que o ameaça em sua dimensão humana tem afetado as instituições de saúde e a enfermagem, danificando seu tecido social, em conseqüência da insuficiência interior decorrente da ausência de espiritualidade".

Embora a dimensão ético-moral-espiritual seja tida como um ideal moral da enfermagem, Maia e Silva ${ }^{(29,30)}$ fazem críticas do vazio do discurso da integralidade, da visão biopsicossocioespiritual, da incompreensão desse conceito no atendimento a pacientes com câncer. Resultados semelhantes foram encontrados por Benko ${ }^{(31)}$, ao investigar a opinião de docentes de enfermagem sobre a assistência espiritual no ensino de graduação. Ele verifica Que "existe falta de clareza também na enfermagem sobre o Que é espiritualidade, religiosidade e assistência espiritual".

Passos $^{(32)}$ apresenta um ensaio em Que analisa os Códigos de Ética de 1958, 1975 e 1993, e aponta para uma mudança de valores no último. Isto nos leva a perguntar: se a lei mudou, por Que os artigos anteriores não refletem essas mudanças?

Em Halbwachs, encontramos uma luz Que nos permite visualizar esta, talvez aparente, contradição Quando nos remete à discussão 
de Que "o espaço coletivo não leva em conta as leis, [...] os costumes locais resistem às forças Que tendem a transformá-lo"(3).

\section{Assistência}

"Se o Que vemos hoje toma lugar no Quadro de referências de nossas lembranças antigas, inversamente essas lembranças se adaptam ao conjunto de nossas percepções presentes"(3). Compartilhando com esta linha de pensamento, agrupamos aQui os artigos Que se referem à forma com Que, ao longo do tempo, os preceitos de espiritualidade e religiosidade tiveram ressonância na assistência: religião e espiritualidade como fator de risco ou de proteção, religião e espiritualidade como requisito para o enfermeiro, religião e espiritualidade como instrumento de trabalho.

Em assistência à saúde, fatores de risco estão relacionados a características individuais ou sociais Que levam a pessoa a tornarse vulnerável a uma situação dada; e fatores de proteção referemse a estas mesmas características, só Que tendem a diminuir a vulnerabilidade. Dentro desta lógica, a religião é apontada tanto como tanto um fator de risco Quanto de proteção; o Que o Qualifica é a reação Que as pessoas têm Quando estão expostas a determinadas situações ${ }^{(33-43)}$.

A exemplo dessas manifestações, "a fé e a oração favorecem a saúde, são terapêuticos"(44), e "as práticas religiosas poderiam intervir no processo saúde-doença mental ao atingirem conotações de integração ou até de desintegração" (45). Informações com relação à religião são importantes porQue têm grande significado nos rituais de nascimento, morte e visões sobre saúde e doença ${ }^{(46)}$.

A religião e a espiritualidade, como requisitos para a prática da enfermagem, é pressuposto Quase cateQuético, permeia a trajetória da enfermagem ao longo dos anos e está impregnado no pensar, no ser e no fazer da profissão.

Este constructo é percebido em trabalhos Que vão desde a aplicação de teorias até experiências pessoais. Mas todos resguardam a religiosidade e a espiritualidade como requisito necessário à prática profissional, seja colocando este reQuisito como um postulado a ser cumprido, seja como resultado de pesquisa onde esse postulado se fez cumprir.

Na Teoria do Cuidado Transpessoal, de Watson, impera a premissa de que "a força interna do ser, sua força espiritual, é capaz de transformar, de curar. [E] para Que isso seja possível, os cuidadores devem reconhecer primeiro em si mesmos esse potencial, como uma postura filosófica, de forma a acreditarem na força interna de todo ser humano"(47), e "a instilação de fé-esperança"(48).

Machado $^{(49)}$, ao relatar sua experiência de Quase morte, coloca a espiritualidade como uma dimensão do ser humano, e adverte que "não faz sentido alguém se prestar a cuidar de pessoas no limite vida/morte sem Que ela mesma tenha despertado para a espiritualidade". Salgado ${ }^{(50)}$ compartilha desta visão e, ao investigar o desconforto dos enfermeiros em abordar este assunto, tem como premissa que "para se ter uma visão integral do ser humano, é preciso admitir a existência da alma ou do espírito e o poder de comando Que este exerce sobre o organismo". Conclui Que, por ser esta uma Questão polêmica no âmbito da ciência, e, conseqüentemente, da saúde, os profissionais têm "postura reservada e insegura".

Esta categoria evidencia um dilema, dilema este provocado pela dualidade entre ser uma profissão de nível universitário, portanto autorizada pelo paradigma científico/positivista, e ter a marca da religião desenhada através do tempo pela consolidação do cristianismo e pelas alianças entre Estado e Igreja.

Esse dilema se evidencia também nos artigos de Araújo ${ }^{(48)} \mathrm{e}$ Rodrigues $^{(51)}$. Ainda em 1978, Araújo ${ }^{(48)}$, partindo da hipótese de Que na prática da enfermagem a assistência à necessidade religiosa no ser humano parece ser negligenciada por parte dos profissionais, pergunta se esta irrelevância está relacionada à formação profissional ou é anterior à sua entrada na universidade. Estudou alunos ingressantes e verificou Que estes têm comportamentos verbais estereotipados em Quase todas as palavras relacionadas a valores religiosos.

Também Rodrigues ${ }^{(51)}$, Quando estuda a concepção de trabalho em alunos do $1^{\circ}$ e $4^{\circ}$ anos, verificou Que em torno da metade deles, ao ingressar na universidade, carregam as características de ajuda, de valorização do contato humano como forma de satisfazer uma necessidade pessoal de ajudar os outros, traços Que coincidem com o modelo religioso vocacional. Já os do $4^{\circ}$ ano apontam para uma profissão, a enfermagem como trabalho, com limites dentro do seu meio. $\mathrm{O}$ autor atribui essa postura a mudanças no currículo, marco Que acredita cumprir o propósito de redirecionar o trabalhador que está sendo formado. Considera, porém, Que esse estudo ainda é muito incipiente.

Com a passagem do tempo, "encontramos inscritos ou indicados os vestígios de acontecimentos ou personalidades de outrora à medida Que respondem e respondem ainda a um interesse ou a uma preocupação do grupo"(3). Se este dilema compõe a melodia do cotidiano, como então fica a concepção do cuidado?

Pedro $^{(52)}$, ao investigar a concepção de cuidado por cuidadores, verifica Que este é percebido como "promoção do desenvolvimento pessoal e espiritual", como a "expressão das mudanças ocorridas no viver cotidiano dos profissionais".

Já Santos ${ }^{(53)}$, ao fazer um retrato detalhado das condições de trabalho dos auxiliares de enfermagem, pergunta como as auxiliares suportam tal conjunto de riscos e inadeQuações? Conclui Que "além do trabalho real, fonte de prazer, são mencionadas pelas entrevistadas as folgas e licenças, é a fé religiosa".

Este panorama vai ao encontro da discussão Que Boaventura Santos faz acerca da ponte entre a ciência moderna e o senso comum: sabemos ou suspeitamos Que as nossas trajectórias de vida pessoais e colectivas (eneuanto comunidades científicas) e os valores, as crenças e os preconceitos Que transportam são a prova íntima do nosso conhecimento, sem o Qual as nossas investigações laboratoriais ou de arQuivo, os nossos cálculos ou os nossos trabalhos de campo constituiriam um emaranhado de diligências absurdas sem fio nem pavio. No entanto, este saber das nossas trajectórias e valores, do Qual podemos ou não ter consciência, corre subterrânea e clandestinamente, nos pressupostos não-ditos do nosso discurso

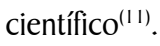

Nesta ponte atravessa também toda a bagagem necessária para instrumentalizar o trabalho, incluindo a religião e espiritualidade, diferente na roupagem, porém semelhante no conteúdo.

$\mathrm{Cruz}^{(36)}$, em publicação sobre as religiões afro-brasileiras, com finalidade de subsidiar o diagnóstico e tratamento da angústia espiritual, de acordo com a Taxonomia I - NANDA, relata que "a espiritualidade é uma dimensão humana na Qual existem fenômenos, como a angústia espiritual Que cabe à enfermeira diagnosticar e 
tratar de forma autônoma”. Horta ${ }^{(54)}$, ao explanar sobre a observação sistematizada como base para o diagnóstico de enfermagem, junta os problemas da ordem psicossocioespirituais e cita a prevalência com Que aparecem.

Gibertoni ${ }^{(39)}$ considera Que "Qualeuer Que seja a crença religiosa da enfermeira, ela deve conhecer as religiões de seus pacientes e por todas as maneiras, encorajar, ver, reforçar essas crenças. O poder da fé é inigualável, e o conforto e a segurança Que a religião oferece é um estímulo à vida".

Aqui temos uma relação íntima entre ideais religiosos aplicados num espaço profano, o da ciência aplicada à assistência, cujo ambiente, via de regra, tem objetivo completamente diferente.

Os artigos, no entanto, revelam-nos Que a devoção transcende aos objetivos apregoados pela ciência, o Que faz com Que "as enfermeiras atribuam a si próprias ou aos demais profissionais da área de saúde, a responsabilidade em preparar psicosocioespiritualmente o paciente para a morte"(55). E "Quanto ao serviço religioso a enfermagem estará sempre em colaboração ora precedendo, ora trabalhando juntamente com o Sacerdote, ora completando sob suas ordens a tarefa divina de reajustamento espiritual aproximando o homem de Deus. Não é possível separar a idéia da enfermagem da caridade cristã $\tilde{a}^{(56)}$.

Este movimento, acredito, por não ter a autorização da comunidade no reconhecimento de ser esta uma prática científica, é então justificado pela necessidade do outro Que deve ser atendida. Considerando que o paciente criticamente enfermo tende a buscar apoio na sua crença religiosa, cabe ao profissional da enfermagem aceitá-la e proporcionar-lhe o atendimento espiritual de Que necessita. Esse atendimento, prestado por pessoas especificamente preparadas para esse fim ${ }^{(57)}$, baseia-se no pressuposto de que "tanto o trabalhador como o usuário dos serviços de saúde-bem estar devem ser cuidados na íntegra de suas dimensões física, emocional, intelectual, social, cultural, espiritual e profissional"(58).

Mesmo em situações em Que não há permissividade à participação dos pacientes em celebrações, é instituído um espaço para práticas religiosas: "os pacientes [psiQuiátricos] não assistem as celebrações, as freiras, às vezes, vão à enfermaria. É permitida a visita de pastores e outros membros das igrejas"(59).

\section{CONSIDERAÇÕES FINAIS}

A título de finalização deste estudo, podemos dizer Que cumprimos as metas traçadas, pois os pontos de interseção entre o discurso da enfermagem e preceitos Que albergam a religião/ religiosidade e espiritualidade foram evidenciados nos trabalhos Que compuseram esta amostragem. No entanto, ainda há muitos mergulhos a serem dados para se descortinarem os reflexos deste nas práticas assistenciais e na organização da profissão.

$\mathrm{Na}$ linha do tempo, os discursos levantados podem ser comparados a uma moeda onde o passado e presente são suas faces, cada uma ocupando um espaço real. Mas, ao mesmo tempo, só existe a moeda se existirem as duas faces, e só identifico a moeda se me for permitido tê-la frente à minha visão e puder olhála dos dois lados, em tempos diferentes.

O Que enxergo se olho esses discursos? Há, de fato, uma raiz religiosa brasileira e esta tem ramificações profundas na conformação da enfermagem brasileira. Esta conformação está tão imbricada na memória coletiva Que, mesmo com a expansão de instituições Que não se declaram religiosas, os pressupostos cristãos se mantêm presentes e com vitalidade.

\section{REFERÊNCIAS}

I. Bittencourt Filho I. Matriz religiosa brasileira: religiosidade e mudança social. Petrópolis (RI) : Vozes; 2003.

2. Biblioteca Virtual em Saúde: fontes de informação. [citado em: 30 abr 2008]. Disponível em: URL: http://www.bvs.br/ php/index.php

3. Halbwachs M. A memória coletiva. São Paulo (SP) : Centauro; 2006.

4. Padilha MICS, Nazário NO, Stipp MAC. O legado e o (re)negado: a enfermagem e as ordens/associações religiosas. Texto Contexto Enferm 1998; 7(1): 71-9.

5. Padilha MICS. O regimento da Santa Casa de Misericórdia do Rio de Janeiro (1 852): um modelo para a enfermagem brasileira do século XIX. Rev Enferm UERJ 1999; 7(2): 136-42.

6. Paixão V. O sentido cristão de servir e a enfermagem. Rev Bras Enferm 1961; 14(4): 303-7.

7. Molina TM. O sentido cristão de servir e a enfermagem. Rev Bras Enferm 1961; 14(4): 31 1-20.

8. Padilha MICS, Mancia JR. Florence Nightingale e as irmãs de caridade: revisitando a história. Rev Bras Enferm 2005; 58(6): 723-6.

9. Santos I, Salles R, Padilha MICS, Silveira MF. Uma nova história da enfermagem. Rev Enferm UERJ 2002; 10(2): 109-13.

10. Grudtner DI. Ajudar o "ser doente" se religar a Deus: também é papel da enfermagem. Cogitare Enferm 1996; I (1): 95-8.

11. Santos BS. Para um novo senso comum: a ciência, o direito e a política na transição paradigmática. $3^{a}$ ed. São Paulo (SP): Cortez; 2001.

12. Borenstein MS, Padilha MICS. O cotidiano de irmãs enfermeiras num hospital de caridade em Florianópolis na década de 50. Esc Anna Nery Rev Enferm 200 I; 5(1): 53-63.

13. Borenstein MS, Pereira VP, Ribas DL, Ribeiro AAA. Historicizando a enfermagem e os pacientes em um hospital psiquiátrico. Rev Bras Enferm 2003; 56(2): 201-5.

14. Pizani MAPN. A atuação de religiosas em Curitiba na assistência aos alienados durante a República Velha. Cogitare Enferm 2002; 7(1): 44-53.

15. Ribeiro AAA, Borenstein MS. Escola de Enfermagem Wenceslau Braz: trajetória e construção da identidade profissional da enfermagem em Itajubá/MG. Texto Contexto Enferm 2003; 12(4): 470-8.

16. Bezerra MRM, Baptista SS. A criação da Escola de Enfermeiras Luiza de Marillac: estratégias para a manutenção do poder da Igreja Católica nos espaços hospitalares. Esc Anna Nery Revi Enferm 2002; 6(2): 241-53.

17. Figueiredo RM, Silva MA. Perfil dos futuros auxiliares de enfermagem da cidade de Campinas, SP, em 1995: motivos, expectativas e dificuldades relacionadas ao curso. Rev Latino- 
am Enfermagem 1997; 5(1): 89-96.

18. Castro E, Sá A. Enfermagem em medicina pastoral: um novo campo para a enfermagem. Rev Bras Enferm 1967; 20(4): 289-94.

19. Almeida Filho AJ, Santos TCF, Baptista SS, Lourenço LHSC. Reunião de diretoras de escolas de enfermagem: um cenário de lutas simbólicas no campo da educação em enfermagem (1943-1945). Texto Contexto Enferm 2005; 14(4): 528-36.

20. Menezes SS, Baptista SS, Barreira IA. O perfil das(os) alunas(os) de enfermagem da Escola Anna Nery: décadas de 20, 30 e 90. Esc Anna Nery Rev Enferm 1998; 2(1/2): 34-48.

21. Gomes TO, Silva BR, Baptista SS, Almeida AJ Filho. Enfermeiras católicas em busca de melhores posições no campo da educação e da prática em enfermagem nos anos 40 e 50 no Brasil, no século XX. Texto Contexto Enferm 2005; 14(4): 506- 12.

22. Gomes TO, Almeida Filho AJ, Baptista SS. Enfermeirasreligiosas na luta por espaço no campo da enfermagem. Rev Bras Enferm 2005; 58(3): 361-6.

23. Rodrigues $E$, Secaf $V$. Religiosas enfermeiras e entidades de classe: atuação na Associação Brasileira de Enfermagem. Rev Paul Enferm 1998; 17(1/3): 15-24

24. Nunes BMVT, Santos AMR, Moura MEB, Silva MEDC, Monteiro CFS, Carvalho ML. Memória coletiva da Associação Brasileira de Enfermagem - Seção Piauí. Rev Bras Enferm 2007; 60(4): 464-9.

25. Portelli H. Gramsci e a Questão religiosa. $2^{\text {a }}$ ed. São Paulo (SP) : Ed. Paulinas; 1984

26. Kant I. A religião nos limites da simples razão. São Paulo (SP): Escala.

27. Dourado HG. O viver ético. Rev Bras Enferm 1957; I0(I): 14-33.

28. Trevizan MA, Mendes IAC, Cury SRR, Mazon L. A dimensão moral e a ação ética no trabalho gerencial da enfermeira. Esc Anna Nery Rev Enferm 2000; 4(2): 181-6.

29. Maia ARC. Elementos e dimensões do cuidado na perspectiva de clientes ambulatoriais. Texto Contexto Enferm 1998; 7(2): 133-50.

30. Silva MAPD, Silva ARB, Silva EM. Oncologia e ética: relações e aproximações. Rev Paul Enferm 200 I ; 20(1): 42-50.

31. Benko MA, Silva MJP. Pensando a espiritualidade no ensino de graduação. Rev Latino-am Enfermagem 1996; 4(1): 7 I-85.

32. Passos ES. A ética na enfermagem. Rev Bras Enferm 1995; 48(I): 85-92.

33. Acioli S. Sentidos e práticas de saúde em grupos populares e a enfermagem em saúde pública. Revista enfermagem UERJ, Rio de laneiro (RI) 2006 jan/mar; I 4(I):2 I -6.

34. Armond LC, Boemer MR. Convivendo com a hospitalização do filho adolescente. Rev Latino-am Enferm 2004; 12(6): 924 32.

35. Azevedo GR, Santos VLCG. Cuida-dor (d)eficiente: as representações sociais de familiares acerca do processo de cuidar. Rev Latino-am Enfermagem 2006; I 4(5): 770-80.

36. Cruz ICF. As religiões afro-brasileiras: subsídios para o estudo da angústia espiritual. Rev Esc Enferm USP 1994; 28(2): 125-36.
37. Dourado VG, Pelloso SM. Gravidez de alto risco: o desejo e a programação de uma gestação. Acta Paul Enferm 2007; 20(1): 69-74.

38. EnriQuez Flores IE, Luis MAV. Uso y actitudes relacionados a las drogas en las estudiantes de enfermería de la Universidad Mayor de San Andrés. Rev Latino-am Enfermagem 2004; I2(n.esp): 376-82.

39. Gibertoni J. Assistência psicológica ao paciente para a cirurgia. Rev Bras Enferm 1967; 20(4): 278-89.

40. Michelone APC, Santos VLCG. Qualidade de vida de adultos com câncer colorretal com e sem ostomia. Rev Latino-am Enfermagem 2004; 12(6): 875-83.

41. Nunes APM, Silva A. Qualidade de vida do aluno-trabalhador do curso de habilitação profissional técnica de nível médio em enfermagem. Online Braz I Nurs 2007; 6(2).

42. Ortega De Medina NM, Osorio Rebolledo EA, Pedrão LJ. El significado de drogas para el estudiante de enfermería según el modelo de creencias en salud de Rosenstock. Rev Latinoam Enfermagem 2004; 12 (n.esp): 3 16-23.

43. Tronchin DMR, Tsunechiro MA. Cuidar e o conviver com o filho prematuro: a experiência do pai. Rev Latino-am Enfermagem 2006; 14(1): 93-101.

44. Ferreira AMTGB, Derntl AM. Ouvindo o idoso hospitalizado: direitos envolvidos na assistência cotidiana de enfermagem. Mundo Saúde 2005; 29(4): 5 I0-22.

45. Machado AL, Cabral MAA. Observação em enfermagem em saúde mental visando as práticas religiosas . Acta Paul Enferm 1996; 9(3): 31-7.

46. Hoga LAK. A influência da crença religiosa na motivação de uma cliente para o autocuidado. Rev Esc Enferm USP 1993; 27(I): 73-85.

47. Vianna ACA, Crossetti MGO. Movimento entre cuidar e cuidar-se em UTI: uma análise através da teoria do cuidado transpessoal de Watson. Rev Gaúcha Enferm 2004; 25(1): 56-69.

48. Araújo EC, Coler MS, Nóbrega MML. Teoria de enfermagem de Jean Watson articulada com a sexualidade humana. Online Braz I Nurs 2005; 4(2).

49. Machado WCA, Figueiredo NMA. Cuidar e ser cuidado: a dimensão subjetiva de uma experiência de Quase-morte. Rev Enferm UERJ 2002; 10(3): 159-64.

50. Salgado APA, Rocha RM, Conti CC. O enfermeiro e a abordagem das Questões religiosas. Rev Enferm UERJ 2007; 15(2): 223-8.

51. Rodrigues RM. Enfermagem compreendida como vocação e sua relação com as atitudes dos enfermeiros frente às condições de trabalho. Rev Latino-am Enfermagem 200I; 9(6): 76-82.

52. Pedro ENR, Funghetto SS. Concepções de cuidado para os cuidadores: um estudo com a criança hospitalizada com câncer. Rev Gaúcha Enferm 2005; 26(2): 2 I0-9.

53. Santos ML. O trabalho dos anjos de branco: um estudo em hospital geral público. Saúde em Debate 1996; (51): 69-74.

54. Horta WA. A observação sistematizada como base para o diagnóstico de enfermagem. Rev Bras Enferm 1971; 24(5): 46-53.

55. Fernandes MFP, Fujimori M, Koizumi MS. Estudo sobre as 
Gussi MA, Dytz ILG.

intervenções de enfermagem frente ao paciente em morte iminente. Rev Bras Enferm 1984; 37(2): 102-8.

56. Nogueira MG. O serviço de enfermagem em face do administrador. Rev Bras Enferm 1956; 9(2): 67-77.

57. Souza M, Possari JF, Mugaiar KHB. Humanização da abordagem nas unidades de terapia Intensiva. Rev Paul Enferm 1985; 5(2): 77-9.
58. Savoldi NA, Neves EP, Santos I, Mauro MYC. Em busca do bem-estar e do modo de ser do trabalhador saudável. Esc Anna Nery Rev Enferm 2003; 7(3): 413-23.

59. Machado AL, Cabral MAA. Enfermarias de psiquiatria em hospital geral: duas experiências na visão de uma enfermeira. J Bras PsiQuiatria 1997; 46(6): 319-23. 